\title{
Sobre passos e cegonhas: as fronteiras de Theodoros Angelopoulos ${ }^{1}$
}

\section{Matheus Lisbôa Matarangas}

Pontifícia Universidade Católica do Rio de Janeiro - PUC-Rio

Departamento de Comunicação Social - Bacharelado em Cinema

\section{Resumo}

Este artigo pretende analisar a representação de fronteiras políticas no filme O Passo Suspenso da Cegonha (1991), do diretor Theodoros Angelopoulos. O realizador será contextualizado dentro da herança cultural de seu país à luz do pensamento de Benedict Anderson e Stuart Hall acerca de culturas e identidades nacionais - conceitos que também serão as bases para o estudo da representação fronteiriça em seus aspectos visuais e com relação à narrativa da obra.

Palavras-chave: Theodoros Angelopoulos; cinema; fronteiras; Benedict Anderson; Stuart Hall.

\section{Introdução}

Um dia cinzento na fronteira entre Grécia e Albânia. Na ponte que concomitantemente une e separa os dois países, uma linha tricolor demarca com precisão o limiar de ambos os territórios. Um militar, acompanhado por um jornalista, se posiciona sobre a demarcação e ergue um dos pés, ficando estático logo em seguida. "Se eu der mais um passo", explica ele, "estarei em 'outro lugar'. Ou morrerei".

O que representa uma fronteira? É esta a questão levantada já na abertura do longametragem O Passo Suspenso da Cegonha (1991), do cineasta grego Theodoros Angelopoulos filme que é o primeiro capítulo de sua Trilogia das Fronteiras, também composta por Um Olhar a Cada Dia (1995) e A Eternidade e Um Dia (1998). Apesar da autoexplicativa alcunha desta tríade, cabe precisar o contexto de sua época: a guerra de partição da Iugoslávia e suas reverberações - tais como as sucessivas ondas de refugiados que afluíram em direção à Grécia.

\footnotetext{
${ }^{1} \mathrm{O}$ presente artigo é um excerto de monografia de graduação em Cinema, orientada pelo professor Gustavo Chataignier, e apresentada em junho de 2021.
} 
Este é o pano de fundo da história do jornalista Alexandros (Gregory Karr), o mesmo que acompanha o militar na cena descrita acima. Ele foi enviado por uma emissora de televisão para cobrir uma vila fronteiriça onde o governo grego aloca os imigrantes que cruzam a fronteira - um microcosmo de toda a crise de refugiados. Seu trabalho, no entanto, ganha novos rumos quando ele avista na multidão um rosto que lhe é familiar: um homem (Marcello Mastroianni) idêntico a um influente político grego que desapareceu por conta própria, sem deixar vestígios. Convencido de que aquela figura é o estadista, Alexandros pede ajuda à esposa abandonada (Jeanne Moreau) e se lança em uma busca para apreender a identidade do misterioso vulto, tal como os motivos que poderiam ter levado o promissor homem público a deixar toda a sua vida para trás.

No meio dessa odisseia pessoal, Alexandros se apaixona pela filha adotiva do personagem de Mastroianni e é nela que a crise em curso se corporifica: a jovem se encontra apartada do noivo por este, diferentemente dela, não ter conseguido deixar a Albânia. Isso obriga o casal a desposar em uma cerimônia que tem lugar nas duas margens do grande rio fronteiriço, com marido e mulher em bordas opostas. Finda a liturgia, o misterioso homem desaparece no dia seguinte. Jamais se esclarece se ele era de fato o político desaparecido - o que, nas palavras de Angelopoulos, "não é relevante.(...) O que é importante é que ele poderia ser o político" (HORTON, 1997, p. 110). Desta forma, Alexandros queda só na cidade fronteiriça, tentando assimilar todas as experiências por ele vivenciadas.

O Passo Suspenso da Cegonha é o foco deste trabalho, no qual será tratada não apenas a forma como Angelopoulos responde à questão já assinalada - o que fronteiras representam mas, também, como fronteiras são representadas por ele. Apesar da filmografia em pauta apresentar e desconstruir as mais diversas categorias de fronteira (presente e passado, individual e coletivo, mítico e real, etc), aqui, o objeto principal será sua abordagem no que tange as fronteiras políticas. Para nos remetermos ao estabelecimento de limites territoriais e à criação das nações que ocupam estes espaços, nosso diálogo será com os autores Stuart Hall e Benedict Anderson, e seus respectivos estudos acerca da identidade cultural, símbolos nacionais e nacionalismo.

Sob estes parâmetros, pretende-se apreender a forma como Theodoros Angelopoulos, um dos mais influentes cineastas do constantemente referenciado, mas parcamente definido, modernismo cinematográfico, expôs e interpretou uma das crises humanitárias mais graves dos anos 1990: a Guerra da Iugoslávia. As interpretações e percepções do diretor acerca de fronteiras e nações ainda se mostram de grande valia em uma época em que crises migratórias são uma constante no cenário internacional. 


\title{
2. Bálcãs: Comunidades Imaginadas e Territórios em Disputa
}

Um refugiado é enforcado nas proximidades de uma estação de trem. Alexandros, o repórter, vai de encontro a seu militar-guia e pergunta o que aconteceu. "Quem me dera saber", responde o coronel. "Eles cruzaram a fronteira para serem livres. Vieram para este mar de lama, traçaram novas fronteiras e tornaram o mundo ainda menor. E sobre os conflitos, nenhuma palavra; a lei do silêncio. Ninguém sabe se foi entre cristãos e muçulmanos, curdos e turcos, ou revolucionários e oportunistas".

O sudeste europeu, como consequência do acesso que proporciona à Ásia, dispõe de flagrante importância estratégica e, portanto, de uma dinâmica bem particular. Desde o século IV a.C, com o império de Alexandre, o Grande, os Bálcãs também foram dominados pelos persas, romanos e turco-otomanos. Das disputas políticas, mas não apenas por causa delas, sucederam-se na região grandes ondas migratórias - a mais notável sendo a dos povos eslavos, oriundos do nordeste da Europa. Dessa zona de intensa disputa e trânsito populacional emergiram, com os movimentos independentistas dos séculos XIX e XX, Estados multiculturais marcados substancialmente por embates étnicos. Em sua obra Comunidades Imaginadas, Benedict Anderson trata do surgimento do nacionalismo grego. Afirma ele:

\begin{abstract}
Em meados do século XVIII, a labuta prodigiosa dos eruditos alemães, franceses e ingleses não só tornara possível, num formato de fácil manejo, praticamente todo o conjunto remanescente de clássicos gregos, com seus devidos anexos filológicos e lexicográficos, como também recriara, em dúzias de livros, uma antiga civilização helênica resplandecente (e decididamente pagã). No último quartel do século, esse "passado" foi se tornando sempre mais acessível a um pequeno número de jovens intelectuais cristãos de língua grega, os quais, em sua maioria, estudaram ou viajaram para fora do Império Otomano. Entusiasmados com o filo-helenismo nos centros da civilização europeia ocidental, eles se dedicaram à "desbarbarização" dos gregos modernos, isto é, à sua transformação em seres dignos de Péricles e Sócrates. (ANDERSON, 2008, p. 113).
\end{abstract}

Através de vários estudos de caso, Anderson aponta um padrão: a construção de discursos nacionalistas se fez presente a partir do final do século XVIII, ganhando força, sobretudo, no século XIX. Há, no entanto, um paradoxo constante: apesar de a construção do ideal de nação ter origem no período moderno, ele se remete a tempos imemoriais. Este é um dos motivos que leva Anderson a definir uma nação como "uma comunidade política imaginada - e imaginada como sendo intrinsecamente limitada e, ao mesmo tempo, soberana" (ANDERSON, 2008, p. 32). Em termos mais específicos: a imaginação teria origem na impossibilidade de um indivíduo conhecer todos os membros de sua nação, mas, ao mesmo tempo, se sentir 
conectado a eles; a limitação, obviamente, no fato de uma nação, por maior que seja, ser sempre finita; a soberania, na materialização do Estado enquanto garantidor da liberdade de uma nação; e a comunidade, na tentativa de se suplantar desigualdades internas aos grupos por conceitos de companheirismo e horizontalidade (ANDERSON, 2008 , p. 32-34). Como o autor descreve:

A ideia de um organismo sociológico atravessando cronologicamente um tempo vazio e homogêneo é uma analogia exata da ideia da nação, que também é concebida como uma comunidade sólida percorrendo constantemente a história, seja em sentido ascendente ou descendente. Um americano nunca vai conhecer e nem sequer saber o nome da imensa maioria de seus 240 milhões de compatriotas. Ele não tem ideia do que estão fazendo a cada momento. Mas tem plena confiança na atividade constante, anônima e simultânea deles. (ANDERSON, 2008, p.56-57).

Um elemento crucial nas comunidades imaginadas, argumenta Anderson, é a "aura de desprendimento" (ANDERSON, 2008, p.202) que elas evocam. Por ser formada por laços que não foram escolhidos, a nação seria supostamente desinteressada e, portanto, poderia solicitar sacrifícios em prol do bem comum. Mais do que pessoas dispostas a matar, os nacionalismos criam pessoas dispostas a morrer.

A ideia de sacrifício supremo vem apenas com uma ideia de pureza, através da fatalidade. Morrer pela pátria, a qual geralmente não se escolhe, assume uma grandeza moral que não pode-se comparar a morrer pelo Partido Trabalhista, pela Associação Médica Americana ou talvez até pela Anistia Internacional, pois estas são entidades nas quais pode-se ingressar ou sair à vontade. (ANDERSON, 2008, p.202).

Esse ideário certamente está em cena nas guerras de partição da Iugoslávia. Diferentes comunidades imaginadas disputam o mesmo espaço físico e seus membros se mostram dispostos a matar e morrer para garanti-lo - como é a suposição do coronel quanto ao homem enforcado na estação de trem. Apesar da impossibilidade de precisar se Theodoros Angelopoulos entrou diretamente em contato com os estudos de Benedict Anderson, há notáveis convergências:

Eu não acredito que a Grécia seja meramente uma localização geográfica. Não é isso que julgo ser importante ou interessante. Para mim, a Grécia é muito maior. Ela se estende para muito além das reais fronteiras do país, pois é a Grécia pela qual buscamos, como um "lar". Então, essa Grécia que está em minha mente é a Grécia que chamo de "casa", não esse escritório ou lugar em Atenas onde estamos conversando. (HORTON, 1999, p. 199). 
O diretor coloca em termos claros como sua visão de Grécia - e, por extensão, aquela que está presente em seus filmes - é um ideal. Ora, sendo ela um ideal, é possível desconstruí-la e erigi-la uma vez mais. O mesmo se dá com o imaginário de outros países. Assim, a partir da Trilogia das Fronteiras, Angelopoulos propõe uma identidade balcânica compartilhada.

\section{E Pluribus Unum}

À permanência de lutas nacionalistas e segregacionistas nos Bálcãs, Angelopoulos responde com um fatalismo latente:

Meu interesse em política e nos Bálcãs é bem fácil de explicar. Olhe para a história deste século e você irá reparar que o primeiro evento significativo ocorreu em Sarajevo [assassinato do Arquiduque Franz Ferdinand, em 1914, deflagrando a Primeira Guerra Mundial], e agora estamos mais uma vez em Sarajevo [palco principal da Guerra da Bósnia, 1992]. Isto prova como nós falhamos. Vivendo nos Balcãs, eu naturalmente estou muito mais perto dos eventos e muito mais preocupado do que o resto da Europa. (ANGELOPOULOS, 2001, p. 100)

Aqui, o diretor traz à baila sua desilusão política. À "falha" deflagrada pela continuidade da beligerância, Angelopoulos visa alvitrar, com seus filmes, novos caminhos possíveis. Em suas palavras: "ao tratar de fronteiras, limites, misturas de idiomas e culturas hoje, estou tentando buscar um novo humanismo, uma nova via" (ANGELOPOULOS, 2001, p. 86, grifo nosso). Em contraposição à reemergência dos nacionalismos balcânicos no final do século XX, o realizador explicita uma proposta de "sonho coletivo". É com essa expressão que se encerra o livro Melancolia do Fim de Século, escrito pelo político desaparecido de O Passo Suspenso da Cegonha. Objetivamente, a derradeira frase é: "Por quais pistas devemos começar um novo sonho coletivo?". Fornecendo a "pista", o diretor preconiza os primeiros passos: o estabelecimento de conexões e a valorização de um passado em comum.

No primeiro filme da trilogia, é o personagem de Marcello Mastroianni o vetor principal do "estabelecimento de conexões". Tanto o célebre político quanto o trabalhador anônimo - sendo eles o mesmo indivíduo ou não - têm como missão de vida a defesa de uma coletividade verdadeiramente plural.

Quanto ao político, a figura que surge é a de um homem inquieto, aparentemente perturbado pelo paradoxo entre sua posição de poder e sua incapacidade de mudar a realidade circundante. Ele é tomado pela "Melancolia do Fim de Século" e propõe "supor[mos] que é 31 
de dezembro de 1999" - de maneira a sugerir uma nova vida para um novo século. Através de seus escritos, ele defende a criação do já citado "sonho coletivo", mas o filme não explicita se ele fornece propostas concretas nesse sentido. Somos levados a crer que é justamente a carência de proposições palpáveis que o leva a desaparecer.

O operário, por sua vez, passa a maior parte do longa envolto em mistério. É só aos 71 minutos de filme que descobrimos a natureza de seu trabalho: ele é encarregado de reparar o cabeamento telefônico da região. A metáfora, sem dúvidas, é explícita: sua função é restabelecer contatos/diálogos entre pessoas. No filme, no entanto, Marcello Mastroianni não é apenas reduzido a um desses operários. O inverso talvez seja mais adequado: esses operários são a expansão de Mastroianni. Desta forma, é primordial nos debruçarmos sobre a edificação da particularidade deste personagem e seus ecos claramente religiosos.

Após avistar o misterioso indivíduo na cidade fronteiriça, Alexandros contacta a esposa do político desaparecido pedindo ajuda para identificar o homem. A mulher se nega de início, mas logo narra ao jornalista seus últimos contatos com o marido: "A época de Natal estava próxima, de novo. Ele parou na frente de um presépio na vitrine de uma loja. Eu não sei o que ele olhava: os três Reis Magos ou a estrela sagrada". Enquanto reconta a situação, ela também observa um grande presépio num centro comercial.

Há, portanto, o estabelecimento de um caráter mítico no(s) personagem(ns) do ator italiano e, uma vez determinado, ele é reforçado com o prosseguimento da narrativa. O primeiro contato efetivo de Alexandros com seu "suspeito" acontece com uma hora de filme. Na presença dos dois está um menino, que parece auxiliar Mastroianni com tarefas diversas. Em troca - nesta cena, ao menos - o jovem cobra a narração de uma história que lhe era devida. Mastroianni, destarte, descreve em tom profético a "Grande Migração" - uma história em que a Terra "começa a queimar, tostada pelo sol", levando todos os povos do mundo a se encontrarem no deserto do Saara e usarem uma pipa para deixar o planeta.

Esse mesmo garoto reaparece ao final do filme, após o sumiço de Mastroianni. Ele declara a Alexandros que viu o homem cruzar a fronteira de mala em mãos e "andando pela água" - em uma referência clara ao Messias cristão. "Ele personifica um dos sentimentos gregos mais profundos, o da espera por um libertador, até mesmo o Messias" (ANGELOPOULOS, 2001, p. 28). Apesar dessa frase ser retirada de uma entrevista sobre o filme Alexandre, O Grande, ela cabe como uma luva na obra aqui analisada. No entanto, nota-se que o libertador neste caso é um anônimo - tanto pela sua posição social quanto pelo fato de desconhecermos sua identidade e até mesmo seu nome - elemento que o potencializa como propagador de ideias. 
Uma questão pertinente que aqui se coloca está ligada ao fato de o personagem de Mastroianni não se restringir a ser um redentor dos gregos, mas sim de uma coletividade plena. Seu principal interesse é a condição de refugiado, com a qual ele próprio se identifica. Em uma de suas falas, o homem enuncia: "Cruzamos a fronteira, mas continuamos lá. Quantas fronteiras temos que cruzar para chegarmos em casa?". Esta breve linha de diálogo ressalta como, para o personagem, ser refugiado é também uma condição psicológica. Isso reverbera com a dinâmica contemporânea das identidades, tal como foi analisada por Stuart Hall (2019).

Em sua obra $A$ Identidade Cultural na Pós-Modernidade, o sociólogo jamaicano se debruça sobre como as identidades nacionais se vêem postas em segundo plano frente a uma noção cada vez mais individual e fragmentada de reconhecimento pessoal. Assim, tal como no exemplo dado sobre o caso americano pelo autor (HALL, 2019, p. 14-15), a identificação de um indivíduo enquanto "negro" ou "feminista" pode preponderar frente a uma recognição da pátria. Essa dinâmica é um dado da contemporaneidade - ou, condição pós-moderna - e está intimamente relacionada com o processo de globalização.

\begin{abstract}
Naquilo que diz respeito às identidades, essa oscilação entre tradição e tradução (...) está se tornando mais evidente num quadro global. Em toda parte, estão emergindo identidades culturais que não são fixas, mas que estão suspensas, em transição, entre diferentes posições; que retiram seus recursos, ao mesmo tempo, de diferentes tradições culturais; e que são o produto desses complicados cruzamentos e misturas culturais que são cada vez mais comuns num mundo globalizado. Pode ser tentador pensar na identidade, na era da globalização, como estando destinada a acabar num lugar ou noutro: ou retornando a suas "raízes" ou desaparecendo através da assimilação e da homogeneização. Mas esse pode ser um falso dilema. (HALL, 2019, p. 52).
\end{abstract}

Hall argumenta que não se pode reduzir os efeitos da globalização a uma mera homogeneização na identidade cultural global. Este processo, além de ocorrer em diferentes graus de intensidade nos centros e nas periferias, gera, ao mesmo tempo, o retorno da identificação ao local/particular, a formação de identidades híbridas e, também, daquelas mais propriamente globalizantes. Em O Passo Suspenso da Cegonha podemos identificar todas essas dinâmicas. Do fortalecimento do regionalismo temos as guerras sectárias nacionalistas que originam a crise sobre a qual o filme se debruça. Os refugiados, em si, apresentam diferentes graus de hibridismo identitário - como a moça albanesa de origem grega por quem Alexandros se apaixona. E, enfim, temos o operário Mastroianni, com sua identidade globalizante, a partir de sua identificação primordial enquanto refugiado. 
Portanto, o conceito de personagem-Messias que Angelopoulos desenvolve só pode ser concebido pela lógica da modernidade tardia. De identidade fragmentada e indefinida, o homem elege um elemento de identificação como o seu principal, de forma a guiá-lo em sua vida. Assim, ao invés de grego, ele é um refugiado que se dedica a outras pessoas em igual situação.

De forma crescente, as paisagens políticas do mundo moderno são fraturadas dessa forma por identificações rivais e deslocantes advindas, especialmente, da erosão da "identidade mestra" da classe e da emergência de novas identidades, pertencentes à nova base política definida pelos novos movimentos sociais: o feminismo, as lutas negras, os movimentos de libertação nacional, os movimentos antinucleares e ecológicos (Mercer, 1990). Uma vez que a identidade muda de acordo com a forma como o sujeito é interpelado ou representado, a identificação não é automática, mas pode ser ganhada ou perdida. Ela tornou-se politizada. Esse processo é, às vezes, descrito como constituindo uma mudança de uma política de identidade (de classe) para uma política de diferença. (HALL, 2019, p. 15-16).

Todos esses elementos alçam o personagem de Mastroianni ao vetor de um ideal que abarca uma perspectiva universalista e inclusiva. Ou, retomando as palavras de Angelopoulos, ele é a materialização do "novo humanismo" concebido pelo diretor.

\section{Simbolizando Arbitrariedades e Transgressões}

Para além de uma postura universalista restrita ao enredo ou a diálogos, Theodoros Angelopoulos traduz imageticamente sua condenação a fronteiras. O diretor erige imagens que versam sobre a aleatoriedade dos limites territoriais, tal como seus impactos a nível individual e coletivo. 
Figura 1: A Fronteira e o Passo Suspenso da Cegonha

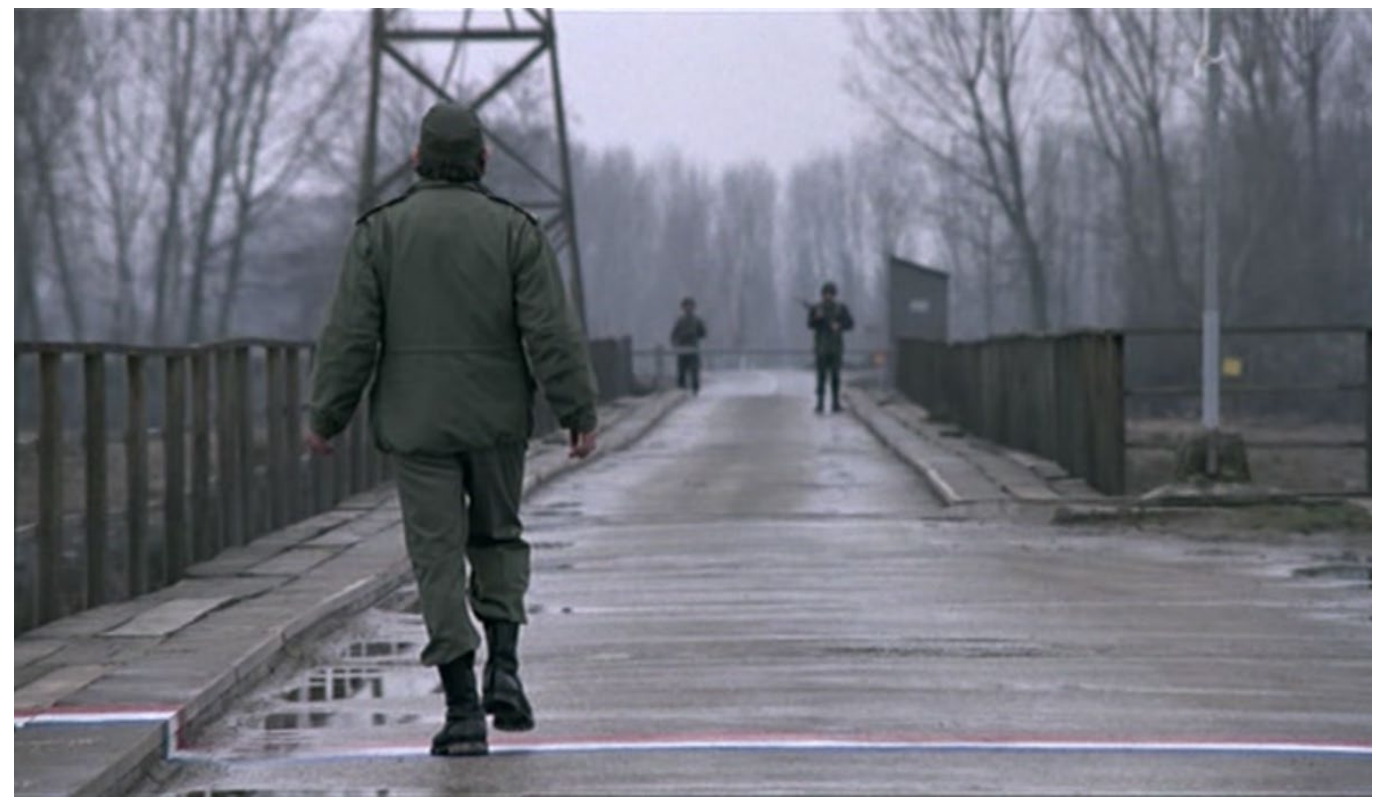

Fonte: ANGELOPOULOS, 1991.

A imagem acima (Figura 1) é da sequência de abertura de O Passo Suspenso da Cegonha descrita na introdução deste trabalho. Esta é a primeira efígie de divisas em toda a Trilogia das Fronteiras. O frame é retirado já do estágio final do plano-sequência, no qual se concretiza um jogo de contrastes. A realização de um zoom-in no militar helênico aproxima-o dos soldados do outro lado da fronteira, como consequência da perspectiva chapada característica das lentes teleobjetivas. Esta proximidade, paradoxalmente, aumenta a percepção de distanciamento entre os lados opostos - desfocando o fundo e não fazendo ver o que de fato há na "outra margem". Este enquadramento não dá grande visibilidade para a fronteira em si as linhas marcadas no chão -, mas sim aos três homens em tela e, sobretudo, à ação do oficial grego - a execução do passo de cegonha. Com essa escolha, Angelopoulos viabiliza em imagem a convicção de que uma fronteira não é um marco no terreno, mas um mecanismo de segregação entre os homens.

Esta imagem reflete bem a forma como Angelopoulos simboliza estremaduras em seus filmes. Elas têm um quê de enigmático - estão muitas vezes tomadas por neblina e neve - e a presença militar é quase sempre certa. Assim, a aura onírica e fictícia ganha graves contornos de hostilidade. Em outras palavras, a fronteira é erigida como um não lugar. 
Figura 2: O Casamento

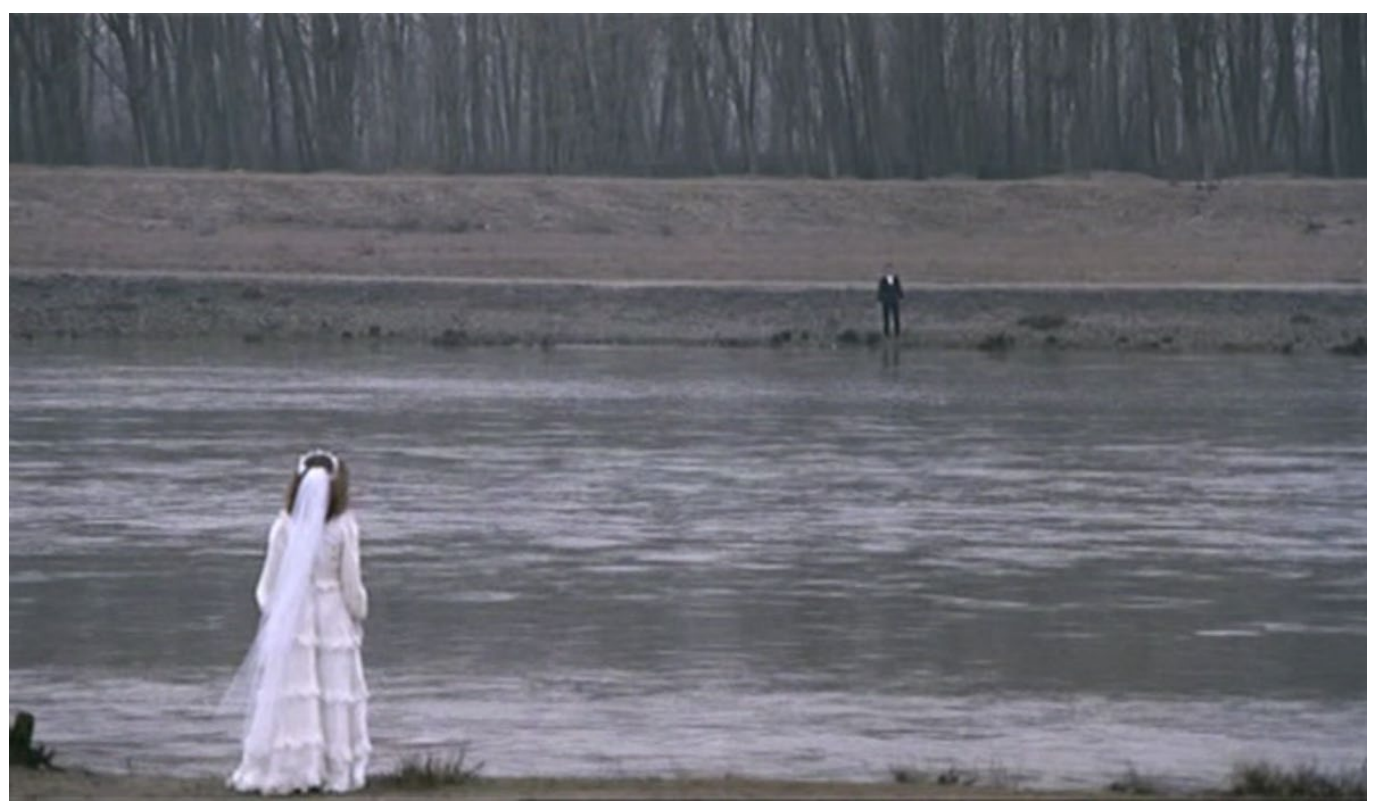

Fonte: ANGELOPOULOS, 1991.

Em O Passo Suspenso, a principal imagem da segregação certamente é o já citado matrimônio (Figura 2) em que marido e mulher se encontram separados apesar de grandes esforços. 0 ponto de vista sempre se dá na banda grega do rio, o que mantém a incógnita acerca do outro lado da fronteira. O frame acima é do único momento em que noivo e noiva são vistos sozinhos no mesmo plano. Não à toa, as águas turvas do rio tomam a maior parte da tela, acentuando a distância entre os dois. Por fim, o casamento é interrompido em seu auge por conta de uma batida militar.

A união dos noivos, no entanto, demonstra, ainda que timidamente, a possibilidade da transcendência - tese firmemente defendida por Angelopoulos. Neste sentido, o plano de encerramento de O Passo Suspenso da Cegonha é notável: na margem do rio fronteiriço, Alexandros presencia a escalada simultânea de toda uma equipe de reparos telefônicos. Estes trabalhadores - cuja equipe, vale lembrar, era integrada por Mastroianni - cruzam a divisa de forma triunfante e coletiva, restabelecendo conexão e comunicação entre os povos (Figura 3). 
Figura 3: Plano final de O Passo Suspenso da Cegonha.

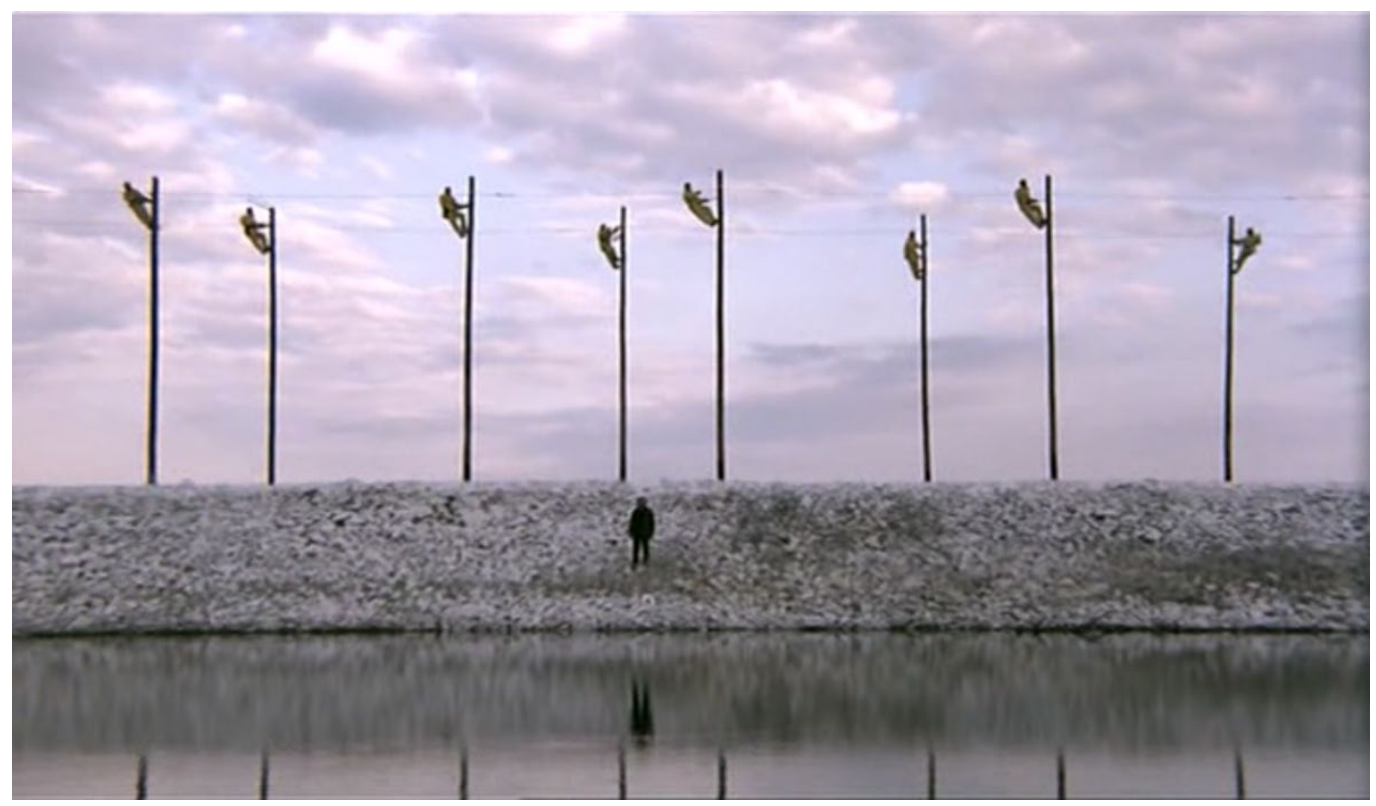

Fonte: ANGELOPOULOS, 1991.

Essa manifestação, no entanto, começa a se desenhar ainda no início do filme. Após efetuar o passo suspenso da cegonha, o coronel é atraído por um som indistinto que tem origem a certa distância. Ele convoca Alexandros para, juntos, verificarem o que se trata. Entram em um jipe e descem a estrada que margeia a banda grega do rio. Em determinado momento, eles saltam do carro, tendo que atravessar uma pequena mata em seguida. Aqui, entretanto, o som já está claro: é música albanesa. Os inquiridores flagram, então, um homem na beira d'água. Ele segura uma pequeníssima jangada, que é ligada por um fio à outra margem. Nela há um tocafitas sobre o qual o homem se debruça. Ele remove a fita cassete que soava até então e a substitui por outra, pressionando o play. Enquanto a jangada é puxada de volta, o aparelho reproduz a música Panselinos $O$ Erotas, da cantora grega Haris Alexiou. 
Figura 4: O "tráfico" de fitas.

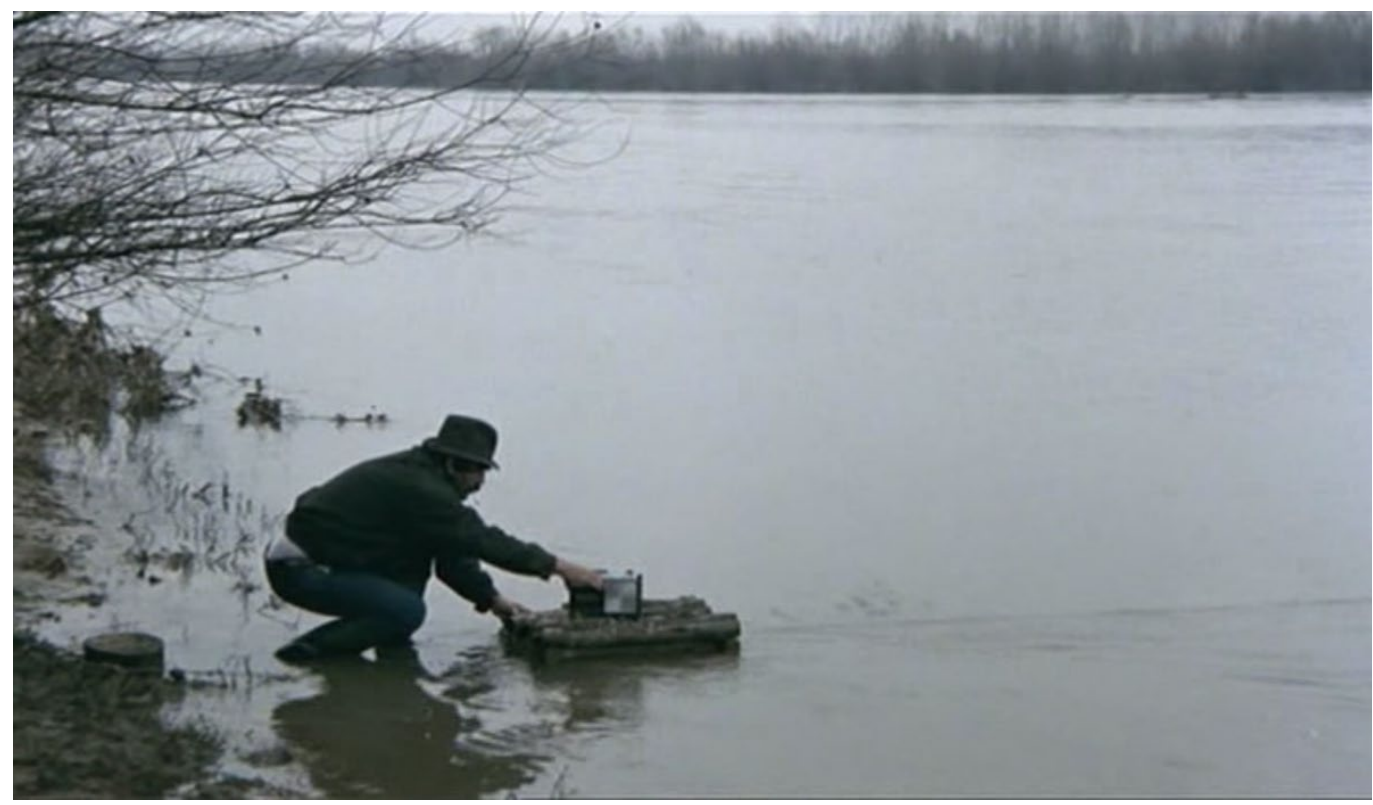

Fonte: ANGELOPOULOS, 1991.

A essa altura do filme, o espectador já tem conhecimento acerca da grave crise de refugiados que embasa a narrativa. Já sabe, também, que a divisão entre Grécia e Albânia é extensivamente vigiada. Apesar de tudo isso, cá estamos: um homem se arrisca, com seus pés enfiados em água e lama por causa de uma simples fita cassete. O que chama a atenção, todavia, é o quão pouco verossímil a situação é. No caso de uma transação proibida, é implausível assumir que ela seria realizada tocando-se as fitas - deflagrando, desta forma, a localização dos envolvidos e o ato em si.

Sem embargo, situações como essa são comuns nos filmes de Angelopoulos. Como define Horton (1999, p. 6, grifo nosso): "Essa tensão particular entre a imagem e seu poder sugestivo, uma base realista e um efeito daquilo que está além do realismo, pode mais utilmente ser descrita como um realismo poético". O que Horton chama de "poder sugestivo" da imagem é, de certa forma, uma instigação de Angelopoulos a seu público. Por isso, a execução das fitas é feita sobretudo para nós, espectadores do filme. O diretor retém o plano por um período considerável para que voltemos nossa atenção às músicas que estão sendo reproduzidas - elementos que fazem parte do discurso de cada uma daquelas comunidades imaginadas; sendo discurso aqui considerado em termos foucaultianos, que, como explica Stuart Hall, representa:

um grupo de pronunciamentos que proporciona uma linguagem para falar sobre um tópico particular ou um momento histórico - uma forma 
de representar o conhecimento sobre tais temas. (...) O discurso tem a ver com a produção de sentido pela linguagem. Contudo, (...) uma vez que todas as práticas sociais implicam sentido, e sentidos definem e influenciam o que fazemos - nossa conduta - todas as práticas têm um aspecto discursivo. (HALL, 1992, p.291 apud HALL, 2016, p.80).

Ademais, define Hall acerca da construção do ideal de nação:

As culturas nacionais são compostas não apenas de instituições culturais, mas também de símbolos e representações. Uma cultura nacional é um discurso - um modo de construir sentidos que influencia e organiza tanto nossas ações quanto a concepção que temos de nós mesmos. As culturas nacionais, ao produzir sentido sobre a "nação", sentidos com os quais podemos nos identificar, constroem identidades. Esses sentidos estão contidos nas histórias que são contadas sobre a nação, memórias que conectam seu presente com seu passado e imagens que dela são construídas. (HALL, 2019, p. 31).

O que Hall observa, desta forma, é que uma nação se entende como tal na medida em que um discurso sobre ela é construído e assimilado. Essa confecção tem formas diversas, já que "todas as práticas [sociais] têm um aspecto discursivo". A língua de uma nação faz parte de seu discurso, assim como sua música e seus rituais. A demonstração trazida pela sequência do tráfico de fitas, então, é do interesse mútuo dos povos acerca da cultura alheia. Para retratar os não limites da fruição artística, Angelopoulos se coloca na posição de observador e argumenta nos seguintes termos:

Eu acredito que meus filmes são sobre jornadas pelas quais todos nós passamos, em qualquer lugar no mundo. O problema de não ter uma casa, um lugar para chamar de seu, é universal. Eu acredito fortemente nisso em todo filme, livro ou trabalho artístico. Quando leio, por exemplo, A Montanha Mágica, de Thomas Mann, não consigo dizer "isso é apenas uma situação alemã". Não. No livro de Mann, eu aprendo algo sobre mim mesmo, sobre todas as pessoas. Sinto o mesmo sobre meus filmes. Esse é o papel da arte. E creio que, quanto mais fundo se vai na história de um local em particular - a Grécia, para mim -, mais universal a obra será para os demais. (HORTON, 1999, p.204).

Para o diretor, diferentemente de exclusão, o compartilhamento de discursos - especialmente por meio de manifestações artísticas - possibilita o mútuo entendimento. A arte perpassa as fronteiras. A mesma noção pode ser expandida para a obra de Angelopoulos como um todo: apesar de serem amplamente calcados no discurso da comunidade imaginada grega, os filmes de Angelopoulos não restringem a fruição de espectadores não gregos. 
Enquanto essa história [da Grécia entre 1939 e 1952 em A Viagem dos Comediantes] é bem conhecida para os gregos, mesmo quando interpretações diferem, ela é menos familiar aos não-gregos. Quando perguntado sobre como o público não-grego poderia se relacionar a essa história obscura, Angelopoulos insistiu que não importa o quão bem um espectador sabe sobre a história da Grécia moderna. Ele relacionou os eventos de forma que aqueles que de fato conhecem a história podem vê-lo como uma crônica específica, enquanto os que não conhecem podem percebê-lo como uma história genérica ou mesmo ficcional. (GEORGAKAS, 1997, p. 35).

O mesmo pode se dizer acerca das diversas alusões que Angelopoulos faz à antiguidade clássica e à tradição bizantina; ou ainda sobre a constante presença de rituais em sua obra. Mesmo que estes sejam alheios à realidade do espectador, Angelopoulos transmite a noção que essas diferenças e particularidades aproximam ao invés de apartar.

\section{Considerações finais}

A complexidade e riqueza da obra de Theodoros Angelopoulos permitem múltiplas análises de seus filmes - levando em conta os mais variados temas. E dentro de sua enxuta filmografia, a Trilogia das Fronteiras tem especial importância. Além de incluir os filmes mais premiados do diretor, a trilogia apresenta uma temática de grande urgência no contexto da época. Não obstante, essa fatia da obra de Angelopoulos permanece extremamente atual, dado que crises migratórias se tornaram uma constante no contexto internacional.

É em O Passo Suspenso da Cegonha que Angelopoulos introduz uma considerável parte dos conceitos que são mais profundamente explorados ao longo da trilogia como um todo. Isso torna o filme um interessante estudo de caso acerca do mote da tríade. Desta forma, análise fílmica de O Passo Suspenso da Cegonha possibilita apontar para a demonstração de fronteiras nacionais em sua aleatoriedade e seu segregacionismo - manifestados tanto na narrativa do longa quanto em suas construções icônicas. Já à luz dos estudos de Stuart Hall e Benedict Anderson, percebe-se na diegese as dinâmicas étnico-nacionais da região e a valorização de uma identidade balcânica compartilhada - identidade esta que não é homogênea. Angelopoulos possui a clara percepção de que a relação entre o particular e o universal é diretamente proporcional, de forma que o intercâmbio entre os variados discursos balcânicos possibilitaria a mútua compreensão e subsequente construção de uma coletividade integral. 


\section{Referências bibliográficas}

ANDERSON, Benedict; Comunidades Imaginadas: reflexões sobre a origem e a difusão do nacionalismo, trad. Denise Bottman, Companhia das Letras, São Paulo, 2008.

ANGELOPOULOS, Theodoros; O Passo Suspenso da Cegonha (To Meteoro Vima TouPelargou). Produção de Theodoros Angelopoulos e Bruno Persery. 126 min. Grécia/ França/ Suíça/ Itália, 1991.

; Theo AngelopoulosInterviews, ed. Dan Fainaru, University

Press of Mississippi, Jackson, 2001.

GEORGAKAS, Dan; Angelopoulos, Greek history and The Traveling Players, In: The Last Modernist: The Films of Theo Angelopoulos, Andrew Horton (ed.), cinema voices series, Flicks Books, Wiltshire, England, ISBN:0-948911-79-4, 1997.

HALL, Stuart; Cultura e Representação, org. Arthur Ituassu, trad. Daniel Miranda e William Oliveira, Ed. PUC-Rio: Apicuri, Rio de Janeiro, 2016.

; A Identidade Cultural na Pós-Modernidade, trad. Tomaz Tadeu da Silva e Guacira Lopes Louro, 12a Edição, Lamparina Editora, Rio de Janeiro, 2019.

HORTON, Andrew; The Films of Theo Angelopoulos: A Cinema of Contemplation, Princeton University Press. Princeton, ISBN: 0-691-01005-6, 1999.

(ed.); The Last Modernist: The Films of Theo Angelopoulos, Flicks Books, Wiltshire, England, ISBN:0-948911-79-4, 1997. 